\title{
Otomatisasi Pembangkitan Mind Map dari Buku Teks Berbahasa Indonesia Berbasis Analisis Struktur Kalimat
}

\author{
Selvia Ferdiana Kusuma ${ }^{\# * 1}$, Daniel O. Siahaan ${ }^{\# 2}$, Chastine Fatichah \#3 \\ \#Program Studi Ilmu Komputer, Institut Teknologi Sepuluh Nopember \\ Jl. Raya ITS, Keputih, Surabaya, Kota SBY, Jawa Timur 60117 \\ ${ }^{1}$ selvia.18051@mhs.its.ac.id \\ ${ }^{2}$ danieldif.its.ac.id \\ ${ }^{3}$ chastinedif.its.ac.id
}

\begin{abstract}
Abstrak- Mind map adalah sebuah media yang dapat digunakan untuk memvisualisasikan keterkaitan suatu informasi. Adanya visualisasi informasi dapat mempermudah pemahaman terhadap informasi tersebut. Tidak ada aturan khusus dalam pembuatan mind map. Namun butuh proses yang cukup panjang ketika ingin membuat sebuah mind map, mulai dari membaca seluruh informasi, memahami keterkaitan informasi, kemudian memvisualisasikan keterkaitan informasi tersebut. Tentunya hal ini akan menyita banyak waktu. Oleh sebab itu penelitian ini mengusulkan sebuah metode otomatisasi pembangkitan mind map berbasis analisis struktur kalimat. Input dari metode ini berupa teks per bab dan outputnya adalah mind map. Setiap kalimat inputan akan diidentifikasi dan dilabeli dengan tag khusus, kemudian dari tag-tag tersebutlah akan dibentuk mind map secara otomatis dengan aturan khusus yang telah dibuat. Uji coba penelitian ini menggunakan lebih dari 1000 kalimat yang divisualisasikan menjadi sebuah mind map. Kemudian hasil visualisasi tersebut divalidasi kebenaranya oleh ahli di bidang pendidikann yang telah memiliki pengalaman mengajar lebih dari 20 tahun. Hasil pegujian yang telah dilakukan menunjukkan bahwa metode yang diusulkan dapat digunakan untuk membangkitkan mind map secara otomatis.
\end{abstract}

Kata kunci - Otomatisasi, Mind Map, Pembangkitan Mind Map, Analisis Struktur Kalimat, Visualisasi Informasi

\section{PEndahuluan}

Mind map adalah suatu cara dalam memvisualisasikan hubungan antar informasi. Adanya visualisasi informasi dapat mempermudah pemahaman terhadap informasi tersebut. Mind map dapat digunakan untuk memvisualisasikan informasi yang ada pada suatu berita [1] maupun membangkitkan pertanyaan [2]. Selain itu di dunia pendidikan mind map dapat digunakan untuk meningkatkan kemampuan analisis siswa [3], meningkatkan skill menulis siswa [4] [5], dan meningkatkan nilai hasil belajar siswa [6]. Tidak ada aturan atau struktur yang baku untuk membuat mind map [1]. Kejelasan dan kelengkapan dalam membuat mind map tergantung dari kreatifitas dan ketelitian dari pembuatnya. Walaupun tidak memiliki aturan yang baku, namun butuh proses yang cukup panjang ketika ingin membuat sebuah mind map. Proses tersebut dimulai dari membaca keseluruhan materi, kemudian membaginya dalam bagianbagian kecil untuk menentukan poin diskusi setiap paragraf, kemudian setelah itu manggabungkan informasi-informasi yang di dapat agar dapat membentuk sebuah mind map. Selama ini sudah banyak tools yang dapat digunakan untuk membantu membuat mind map. Namun tools yang ada hanya membantu untuk memvisualisasikan. Pengguna harus tetap membaca kemudian merancang mind mapnya sendiri.

Sampai saat ini masih jarang penelitian terkait pembangkitan mind map secara otomatis. Saelan \& Purwarianti dalam penelitiannya yang berjudul Generating Mind Map from Indonesian Text using Natural Language Processing Tools mencoba membuat mind map yang berasal dari teks berbahasa Indonesia menggunakan analisis semantik [7]. Sedangkan Yulianto \& Mariyah dalam penelitiannya yang berjudul Automatic Mind Map Generator For Natural Disaster News in Bahasa Indonesia mencoba membangkitkan visualisasi informasi berupa mind map dari kalimat berita berbahasa Indonesia. Pembuatan mind map yang dilakukan berbasis matrik dari kumpulan fitur yang telah dipilih [1]. Selain kedua penelitian tersebut juga ada satu penelitian terkait otomatisasi pembangkitan mind map yang menggunakan bahasa Inggris. Elhoseiny \& Elgammal dalam penelitiannya yang berjudul English2MindMap: an Automated System for MindMap Generation from English Text mencoba membangkitkan mind map dari teks berbahasa inggris menggunakan Detailed Meaning Representation (DMR) dan Multi Level MR Generation (MLMR) [8]. 
Penelitian terkait visualisasi teks yang sering dilakukan adalah berbasis concept map [9] [10] [11] [12] [13]. Visualisasi dengan concept map berfokus pada representasi konsep dan relasi antar konsep. Kelebihan dari concept map adalah visualisasi informasi yang ditampilkan sangat lengkap. Namun kelemahannya adalah sulit dipahami karena visualisasinya terlihat kompleks. Sedangkan visualisasi menggunakan mind map cenderung lebih simpel walaupun tidak disertai relasi informasi yang jelas. Kedua jenis visualisasi tersebut memiliki kelebihan dan kelemahan masing-masing.

Kontribusi dari penelitian ini adalah melakukan otomatisasi visualisasi informasi dari buku teks akademik. Proses visualisasi dilakukan dengan menggabungkan konsep mind map dan concept map agar menghasilkan visualisasi keterkaitan informasi yang jelas namun tidak komplek.

\section{Penelitian Terdahulu}

Penelitian terkait otomatisasi pembangkitan mind map sampai saat ini masih jarang dilakukan. Hanya ada 2 penelitian berbahasa Indonesia dan 1 penelitian berbahasa Inggris terkait otomatisasi pembangkitan mind map.

Penelitian pertama yang menggunakan Bahasa Indonesia untuk membangkitkan mind map secara otomatis dilakukan oleh Saelan \& Purwarianti. Metode yang digunakan berbasis analisis semantik [7]. Analisis semantik yang dimaksud terdiri dari Indonesian POS Tagger, Indonesian PCFG Parser, and Indonesian FOL Semantic Analyzer. Hasil yang didapatkan masih memiliki akurasi yang rendah untuk kalimat yang komplek karena masih memunculkan objek yang tidak penting, namun ketika kalimat kompleks tersebut disederhanakan hasil akurasinya dapat meningkat drastis.

Penelitian kedua yang menggunakan Bahasa Indonesia untuk membangkitkan mind map secara otomatis dilakukan oleh Yulianto \& Mariyah. Penelitian tersebut berfokus pada pembangkitan mind map yang berasal dari kalimat berita [1]. Metode yang digunakan berbasis matrik yang terdiri dari beberapa fitur. Fitur yang digunakan yaitu bag of word (BOW) dan term frequency-inverse document frequency (TF-IDF). Selain itu ada 3 filterisasi fitur yang terdiri dari positif keyword (F2), sentence centrality (F4) dan kesamaan kalimat (F5). Fitur-fitur yang didapatkan kemudian digunakan untuk melakukan summarization dan mengklasifikasikan informasi berdasarkan $5 \mathrm{~W}+1 \mathrm{H}$ kemudian menggabungkannya menjadi sebuah mind map. Akurasi yang didapat dari penelitian ini adalah $78.5 \%$. Walaupun penelitian ini memiliki akurasi yang baik, namun tidak dijelaskan secara detil bagaimana contoh hasil mind map yang terbentuk. Penelitian ini hanya menjelaskan dapat membangkitkan mind map berdasarkan informasi $5 \mathrm{~W}+1 \mathrm{H}$. Di bidang akandemik, informasi terkait $5 \mathrm{~W}+1 \mathrm{H}$ ini perlu didetilkan lagi menjadi bagian lebih spesifik seperti terkait informasi bertipe definisi, daftar subjek, sebab akibat, alasan, metode, entitas, lokasi, and waktu [14].

Penelitian lain terkait mind map yang menggunakan bahasa Inggris dilakukan oleh Elhoseiny \& Elgammal [8].
Metode yang digunakan berbasis Detailed Meaning Representation (DMR) untuk merepresentasikan informasi dari sebuah kalimat. Penelitian ini juga menggunakan Multi Level MR Generation (MLMR) untuk merepresentasikan informasi yang lebih detil. Hasil yang di dapatkan dari proses MR dan MLMR kemudian akan digunakan sebagai dasar pebuatan mind map. Hasil eksperimen yang telah dilakukan menunjukkan hasil yang cukup memuaskan yaitu dengan hasil satisfaction ratio rata-rata lebih dari 0.84 . Namun perbedaan struktur kalimat pada Bahasa Indonesia dan Bahasa Inggris membuat metode ini tidak sesuai jika diterapkan untuk Bahasa Indonesia.

\section{METODE}

Penelitian ini memiliki 2 tahapan yaitu identifikasi kalimat dan pembangkitan mind map. Penelitian ini berfokus pada pengenalan struktur dari kalimat. Pembuatan mind map tergantung pada setiap kata maupun setiap tanda baca yang ada pada kalimat tersebut. Secara detil dijelaskan pada sub bab berikut.

\section{A. Data}

Dataset yang digunakan adalah buku BSE mata pelajaran Ilmu Pengetahuan Alam (IPA) dari kemendikbud yang mengacu pada kurikulum 2008. Buku BSE yang digunakan sebagai acuan ditunjukkan pada Tabel 1.

TABEL I

Buku BSE SEbAGAi ACUAN DATASET

\begin{tabular}{|c|l|l|l|}
\hline No & \multicolumn{1}{|c|}{ Judul Buku } & \multicolumn{1}{|c|}{ Pengarang } & \multicolumn{1}{|c|}{ ISBN } \\
\hline 1 & $\begin{array}{l}\text { Ilmu Pengetahuan } \\
\text { Alam Untuk SD dan }\end{array}$ & $\begin{array}{l}\text { Heri Sulistyanto } \\
\text { \& Edy Wiyono }\end{array}$ & $\begin{array}{l}979- \\
462-\end{array}$ \\
& MI Kelas 5 & & $954-5$ \\
\hline 2 & Senang Belajar Ilmu & S. Rositawaty \& & $979-$ \\
& Pengetahuan Alam 6 & Aris Muharam & $462-848$ \\
& & & 4 \\
\hline
\end{tabular}

Kalimat-kalimat pada buku inilah yang nantinya akan dibentuk sebagai mind map. Tiga bab dari buku Ilmu IPA kelas 5 akan digunakan sebagai data latih dan tiga bab dari buku IPA kelas 6 akan digunakan sebagai data uji. Data latih digunakan untuk menemukan rule terkait tentang bagaimana sebuah kalimat dapat diubah menjadi mind map. Rule dibuat dengan membandingkan antara kalimat yang digunakan untuk membuat mind map dan mind map yang terbentuk. Data uji digunakan untuk menguji bagaimana kinerja rule yang telah dibuat. Perbedaan kelas yang digunakan berfungsi untuk melihat kinerja metode terhadap jenis kalimat dari pengarang yang berbeda dan untuk kelas yang berbeda.

\section{B. Identifikasi Kalimat}

Identifikasi kalimat diperlukan untuk mengetahui bagaimana kalimat tersebut dapat dibentuk menjadi mind map. Identifikasi kalimat dilakukan melalui pelabelan dan pengkodean. Alur proses identifikasi kalimat ditunjukkan pada gambar 1. Inputan proses ini adalah sebuah paragraf, 
kemudian paragraf tersebut di ekstraksi sehingga menghasilkan pecahan per kalimat. Setiap kalimat kemudian dilabeli sesuai label pada pos tag, tujuannya adalah untuk menentukan dimana letak verb berada. Setelah verb diketemukan kemudian dilakukan pelabelan khusus yang berfokus pada kata kunci, kata kerja, preposisi, entitas, koma dan konjungsi.

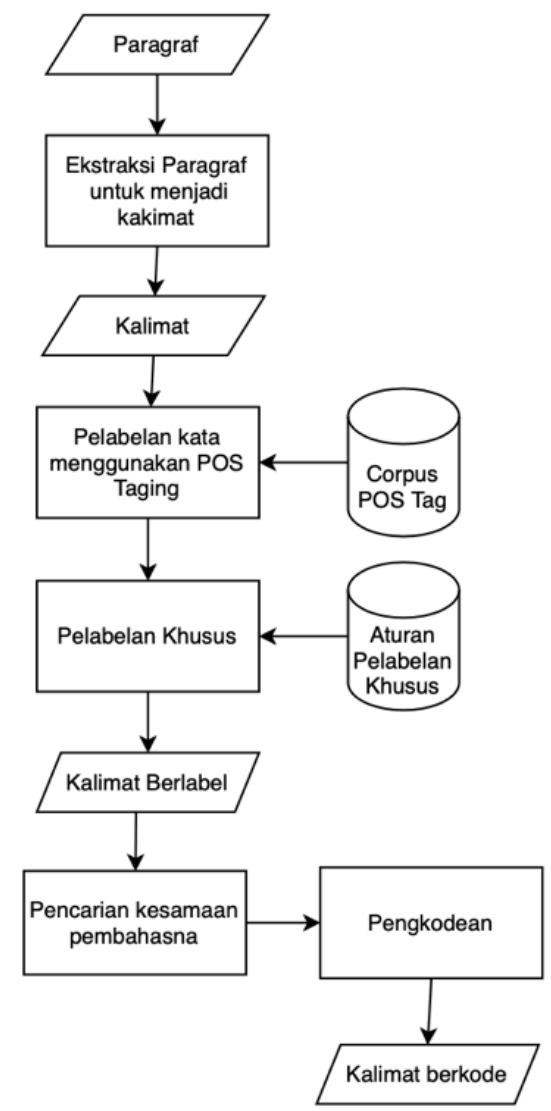

Gambar 1. Proses identifikasi kalimat

Pelabelan yang dilakukan akan dapat membantu menunjukkan bagian mana dari kalimat tersebut yang akan digunakan sebagai cabang dari mind map [15]. Pelabelan dilakukan menggunakan aturan leksikal pada POS Tagging [16]. Jenis pelabelan yang digunakan masuk pada kriteria pelabelan semantik yang berarti penggambaran konsep beserta relasinya dalam representasi Conceptual Ontological Graph (COG) [17]. Pelabelan yang dilakukan yaitu penandaan kata yang berupa kata kunci, kata kerja, preposisi, entitas, koma dan konjungsi. Kata kunci yang digunakan terbagi berdasarkan jenis kalimatnya. Ada 8 jenis kalimat yaitu definisi, daftar subjek, sebab akibat, alasan, method, lokasi, subjek, dan waktu [9]. Kata kunci untuk tiap jenis kalimat ditunjukkan pada Tabel 2.
TABEL III

Jenis KaLimat BeSERTA Kata KunCi [9]

\begin{tabular}{|c|c|c|}
\hline No & $\begin{array}{c}\text { Jenis } \\
\text { Kalimat }\end{array}$ & Keyword \\
\hline 1 & Definisi & merupakan, adalah, ialah, disebut \\
\hline 2 & $\begin{array}{l}\text { Daftar } \\
\text { subjek }\end{array}$ & $\begin{array}{l}\text { yaitu,sebagai berikut, meliputi, } \\
\text { terdiri dari }\end{array}$ \\
\hline 3 & $\begin{array}{l}\text { Sebab } \\
\text { Akibat }\end{array}$ & $\begin{array}{l}\text { disebabkan, disebabkan oleh, } \\
\text { dipengaruhi oleh, sehingga, } \\
\text { menimbulkan, berakibat pada, jika- } \\
\text { maka, apabila- maka }\end{array}$ \\
\hline 4 & Alasan & $\begin{array}{l}\text { Karena, oleh karena, apabila, bila, } \\
\text { terjadi karena, terjadi akibat, agar, } \\
\text { akibat }\end{array}$ \\
\hline 5 & Method & $\begin{array}{l}\text { Dengan, secara, dengan cara, } \\
\text { melalui proses, cara, proses }\end{array}$ \\
\hline 6 & Lokasi & Menuju, di, ke, dari, pada, dalam \\
\hline 7 & Subjek & Oleh \\
\hline 8 & Waktu & pada, terjadi ketika, ketika, sejak \\
\hline
\end{tabular}

Hasil dari pelabelan kemudian masuk pada proses pencarian kesamaan pembahasan kata. Setelah proses pencarian kesamaan kata kemudian masuk ke proses pengkodean. Proses pengkodean dilakukan berdasarkan algoritma khusus yang telah dibuat agar dapat memberikan kode berdasarkan kesamaan kata maupun jenis label yang digunakan. Ilustrasi dari proses identifikasi kalimat akan dijelaskan sebagai beikut:

Mind map yang dibangun terbentuk dari 3 bagian yaitu subjek 1, relasi dan subjek 2. Representasi COG menangkap konsep-konsep dan relasi di antara konsepkonsep tersebut. Alasan penggunaan label dan cara pelabelan secara detil akan dijelaskan sebagai berikut:

1) Algoritma Pelabelan Jenis <Number>: Label ini digunakan jika ada angka atau huruf dan tanda titik di awal kalimat maka akan ditandai sebagai <number>. Kalimat setelah label <number> selalu dianggap sebagai <sentence> karena nantinya ia akan menjadi subjek utama pada mind map. Contoh kalimatnya adalah:

- A.Alat pernapasan manusia dan hewan.

- 1. Alat pernapasan manusia."

Pseudocode yang terbentuk adalah:

Start

Input: Sentence

If (ada angka/huruf dan titik di awal kalimat)

Tandai angka/huruf sebagai <number>

Tandai kalimat setelahnya <sentence> Else

Lanjut ke pencarian lain

Output: Sentence with lebel

End

Contoh hasil outputnya:

A. $<$ number $>\quad$ Alat pernapasan manusia dan hewan<sentence $>$.

$1 .<$ number $>$ Alat pernapasa pada manusia $<$ sentence $>$. 
2) Algoritma Pelabelan Jenis $\langle$ Verb $\rangle$ dan $\langle$ In $\rangle$ : Label ini digunakan ketika ada kata yang berjenis kata kerja <verb> dan konjungsi <in> diketemukan. Pelabelan kata berjenis <verb > dan <in> perlu dilakukan karena mayoritas informasi dari subjek muncul setelah <verb> atau <verb + in> yang diketemukan.

Contoh kalimatnya adalah "Semua burung bernapas dengan paru-paru.".

Pseudocode yang terbentuk adalah:

Start

Input: Sentence

If (jenis kata=verb)

Tandai kata sebagai <verb>

Else if (jenis kata=in)

Tandai kata sebgai <in>

Else

Lanjut ke pencarian lain

Output: Sentence with lebel

End

Contoh hasil outputnya : Semua burung $\langle$ sentence $>$ bernapas <verb> dengan<in > paru-paru<entity> .

3) Algoritma Pelabelan Jenis Koma 〈comma>: Label ini digunakan ketika ada koma pada kalimat tersebut. Label koma ini nantinya digunakan untuk mengetahui keberadaan daftar entitas dari sebuah kalimat. Selain itu juga digunakan untuk mengetahui dimana letak kalimat utamanya. Jika ada lebih dari 1 koma dalam 1 kalimat berarti kalimat tersebut terdiri dari beberapa daftar kalimat. Namun jika hanya ada 1 koma berarti ada kalimat utama dan kalimat pelengkap di dalam 1 kalimat tersebut.

Contoh kalimatnya adalah:

- Tipe 1: "Alat pernapasan pada manusia terdiri dari rongga hidung, pangkal tenggorok, tenggorok (trakea), dan paru-paru.".

- Tipe 2: Di dalam hidung, udara mengalami penyaringan sehingga debu atau kotoran yang berasal dari udara tidak dapat masuk.

Pseudocode yang terbentuk adalah:

Start

Input: Sentence

If (koma diketemukan)

Tandai comma sebagai <comma>

Else

Lanjut ke pencarian lain

Output: Sentence with lebel

End

Contoh hasil outputnya:

- Tipe 1: Alat pernapasan pada<sentence $>$ manusia terdiri dari<verb + Partikel $>$ rongga hidung<entity $>$, $<$ comma $>$ pangkal tenggorok<entity $>$, <comma $>$ tenggorok (trakea) <entity $\rangle,<$ comma $>$ dan paruparu<entity>.

- Tipe 2: Di dalam hidung <sentence>, <comma> udara mengalami<verb> penyaringan sehingga debu atau kotoran yang berasal dari udara tidak dapat masuk<sentence $>$.
4) Algoritma Pelabelan Jenis <entity>: Label ini digunakan ketika ada kata yang berada setelah koma atau diantara kata "dan". Kata berlabel seperti ini nantinya akan digunakan untuk membentuk subjek baru. Namun tidak semua kata setelah koma akan menjadi entitas. Kata akan berlabel entitas hanya jika ada lebih dari 1 koma dalam kalimat tersebut.

Contoh kalimatnya adalah:

- $\quad$ Tipe 1: "Alat pernapasan pada manusia terdiri dari rongga hidung, pangkal tenggorok, tenggorok (trakea), dan paru-paru.".

Pseudocode yang terbentuk adalah:

Start

Input: Sentence

If $($ Comma $>1)$

Tandai kata setelah verb sebagai <entity>

Tandai kata setelah comma sebagai <entity>

Tandai kata setelah keyword "dan" sebagai entity

Else

Lanjut ke pencarian lain

Output: Sentence with lebel

End

Contoh hasil outputnya:

- Tipe 1: Alat pernapasan pada<sentence> manusia terdiri dari<verb + Partikel $>$ rongga hidung $<$ entity>,<comma> pangkal tenggorok <entity>, $<$ comma $>$ tenggorok (trakea) $<$ entity $>,<$ comma $>$ dan paru-paru<entity>.

\section{5) Algoritma Pelabelan Jenis}

Konjungsi<Conjuction>: Label ini digunakan ketika ada konjungsi khususnya "dan" dan "serta" digunakan. Keberadaan konjungsi berupa kata "dan" dan "serta" perlu ditandai karena mengindikasikan entitas. Jika ada lebih dari satu entitas maka mind map akan membentuk cabang informasi.

Contoh kalimatnya adalah "Penyaringan ini dilakukan oleh rambut hidung dan selaput lendir".

Pseudocode yang terbentuk adalah:

Start

Input: Sentence

If (conjuction diketemukan) Tandai kata sebelum dan sesudah konjungsi sebagai <entity>

Else

Lanjut ke pencarian lain

Output: Sentence with lebel + Rule

End

Contoh hasil outputnya: Penyaringan ini $<$ Sentence $>$ dilakukan $<$ verb $>$ oleh $<$ in $>$ rambut hidung $<$ entity $>\quad$ dan $<$ conjuction $>\quad$ selaput lendir<entity>.

6) Algoritma Pelabelan Jenis Kata Kunci $\langle$ Keyword $>$ : Label ini digunakan ketika ada kata kunci seperti yang ditunjukkan pada tabel 3 terdeteksi. Keberadaan kata kunci dapat digunakan untuk mempermudah pembentukan mind map.

Contoh kalimatnya adalah: Cabang tenggorok disebut bronkus". 
Pseudocode yang terbentuk adalah:

Start

Input: Sentence

If (keyword diketemukan)

Tandai kata sebagai <keyword>

Tandai kata sebelumnya sebagai sentence

Cek keberadaan <entity> setelah keyword

Else

Lanjut ke pencarian lain

Output: Sentence with lebel

End

- Contoh hasil outputnya: Cabang tenggorok <sentence > disebut<keyword $>$ bronkus<entity>.

7) Algoritma Pelabelan Jenis <Sentence $>$ : Label ini digunakan ketika ada kata atau kumpulan kata selain yang sudah terdeteksi sebelumnya. Keberadaan kalimat bertanda <sentence> memudahkan untuk digunakan sebagai kalimat yang perlu dicek.

Contoh kalimatnya adalah: Cabang tenggorok disebut bronkus".

Pseudocode yang terbentuk adalah:

Start

Input: Sentence

If (ada kata yang tidak terdeteksi)

Tandai kata sebagai <sentence>

If ( 2 / lebih sentence berdekatan)

Tandai kalimat tersebut sebagai

<sentence>

Else

Else

Lanjut ke output

Lanjut ke pencarian lain

Output: Sentence with lebel

End

- Contoh hasil outputnya: Cabang tenggorokan $<$ sentence $>$ disebut $<$ keyword $>$ bronkus <entity $>$.

Setelah pelabelan kata, juga ada proses pemberian kode untuk setiap kata/kalimat yang berlabel. Fungsi dari pemberian kode tersebut agar dapat mengetahui keterkaitan antar pembahasan. Sebelum proses pengkodean, ada proses pengecekan kesamaan subjek pembahasan. Proses pengecekan kesamaan dilakukan berdasarkan kesamaan kata. Root dari mind map akan diberi angka 1 digit. Apabila root tersebut memiliki cabang maka cabangnya akan ditandai dengan penambahan 1 digit angka 1 menjadi 1.1 . Apabila root memiliki 2 cabang maka penomorannya menjadi 1.1 dan 1.2. Penjelasan rinci terkait aturan pemberian kode dijelaskan sebagai beikut:

1. Jika bertemu dengan kata yang berlabel <number> jadikan kalimat tersebut sebagai root/subjek pada mind map. Tapi jika kalimat setelah label <number> memiliki kesamaan maka gunakan penghubung kata "terkait tentang" sebelum membuat subjek pembahasan baru. Ketika sudah ada keyword "terkait tentang" berarti langsung merujuk ke kata "terkait tentang".
Contoh paragrafnya adalah:

- A.<number $>$ Alat Pernapasan pada Manusia dan Hewan<sentence $>$

- $1 .<$ number $>$ Alat Pernapasan pada Manusia<sentence>

- 2.<number $>$ Alat Pernapasan pada Hewan <sentence>

Contoh hasil output ditunjukkan pada tabel 3.

TABEL IIIII

Hasil PENGKodeAn LABEL NUMBer

\begin{tabular}{|l|l|l|}
\hline Kode & Parent & \multicolumn{1}{c|}{ Kata / Kalimat } \\
\hline 1 & - & $\begin{array}{l}\text { Alat pernapasan pada hewan dan } \\
\text { manusia }\end{array}$ \\
\hline 1.1 & 1 & (x) terkait tentang \\
\hline 1.1 .1 & 1.1 & Alat pernapasan pada manusia \\
\hline 1.1 .2 & 1.1 & Alat pernapasan pada hewan \\
\hline
\end{tabular}

2. Jika bertemu dengan verb / verb+partikel gunakan kata berlabel verb tersebut sebagai sub pembahasan. Jika ada comma berarti akan ada cabang pembahasan. Contoh kalimatnya adalah: Alat pernapasan manusia<sentence> terdiri $i_{\text {verb }}$ dari<partikel> hidung $<$ entity $>,\langle$ comma> pangkal tenggorokan $<$ entity $>,<c o m m a>$ trakea $<$ entity $><$ comma $>$ dan $<$ conjuction> paruparu $_{<\text {entity }>\text {. Contoh hasil output ditunjukkan pada tabel }}$ 4.

TABEL IVV

Hasil PengKodean Label Verb, Koma, DAN KonJUgasi

\begin{tabular}{|l|l|l|}
\hline \multicolumn{1}{|c|}{ Kode } & Parent & \multicolumn{1}{c|}{ Kata / Kalimat } \\
\hline 1.1 .1 .1 & 1.1 .1 & (x) Terdiri dari \\
\hline 1.1 .1 .1 .1 & 1.1 .1 .1 & Hidung \\
\hline 1.1 .1 .1 .2 & 1.1 .1 .1 & Pangkal tenggorokan \\
\hline 1.1 .1 .1 .3 & 1.1 .1 .1 & Trakea \\
\hline 1.1 .1 .1 .4 & 1.1 .1 .1 & Paru-paru \\
\hline
\end{tabular}

3. Jika diketemukan keyword maka gunakan kata berlabel <keyword > sebagai sub pembahasan. Contoh kalimatnya adalah: Cabang trakea ssentence> $_{\text {> }}$ disebut $_{<\text {keyword }>}$ bronkus $<$ sentence $>$. Contoh hasil output ditunjukkan pada tabel 5 .

TABEL V

Hasil PENGKOdEAN Label Kata KunC

\begin{tabular}{|l|l|l|}
\hline \multicolumn{1}{|c|}{ Kode } & \multicolumn{1}{c|}{ Parent } & \multicolumn{1}{c|}{ Kata / Kalimat } \\
\hline 1.1 .1 .1 .3 .1 & 1.1 .1 .1 .3 & Cabang (x) disebut \\
\hline 1.1 .1 .1 .3 .1 .1 & 1.1 .1 .1 .3 .1 & bronkus \\
\hline
\end{tabular}

4. Terkadang 1 kalimat bisa terdiri dari kata kunci dan kata kerja. Gunakan kata kunci sebagai penanda sub pembahasan. Contoh kalimatnya adalah: Cabang trakea ${ }_{<\text {sentence }}$ disebut $_{<\text {keyword }>\text { bronkus }}<$ sentence $>$. Contoh hasil output ditunjukkan pada tabel 6 
TABEL VI

HASIl PENGKODEAN LABEL VERB+KATA KUNCI

\begin{tabular}{|l|l|l|}
\hline \multicolumn{1}{|c|}{ Kode } & \multicolumn{1}{c|}{ Parent } & \multicolumn{1}{c|}{ Kata / Kalimat } \\
\hline 1.1 .1 .1$. & 1.1 .1 .1 .3 .1 .1 & (x) memiliki cabang \\
3.1 .1 .1 & & yang disebut \\
\hline 1.1 .1 .1$. & 1.1 .1 .1 .3 .1 .1 .1 & bronkus \\
3.1 .1 .1 .1 & & \\
\hline
\end{tabular}

5. Jika hanya ada 1 comma gunakan <sentence> sebelum <comma untuk mencari kesamaan pembahasan, jika tidak ada, abaikan keseluruhan kalimat tersebut. Contoh kalimatnya adalah: Di dalam hidung $_{<\text {sentence }>,<\text { comma> }}$ udara $<$ sentence $>$ mengalami $_{<\text {verb }}>$ penyaringan $_{\langle\text {sentence }>}$. Contoh hasil output ditunjukkan pada tabel 7 .

TABEL VII

Hasil PengKodean Label Satu Label Koma

\begin{tabular}{|l|l|l|}
\hline \multicolumn{1}{|c|}{ Kode } & \multicolumn{1}{c|}{ Parent } & \multicolumn{1}{c|}{ Kata / Kalimat } \\
\hline 1.1.1.1.1.1 & 1.1 .1 .1 & $\begin{array}{l}\text { Di dalam (x) Udara } \\
\text { mengalami }\end{array}$ \\
\hline $\begin{array}{l}1.1 .1 .1 . \\
1.1 .1\end{array}$ & 1.1 .1 .1 .1 & Penyaringan \\
\hline
\end{tabular}

6. Jika diketemukan kata ganti "nya",maka gunakan subjek pertama kalimat sebelumnya menjadi sebagai sub pembahasan. Jika diketemukan kata "ini"/ "itu" maka gunamakan kata sebelum kata ini "ini"/ "itu" pada kalimat sebelumnya sebagai root. Contoh kalimatnya adalah: Di dalam hidung sentence $>,\langle$ comma $>$ udara $<$ sentence> mengalami <verb> penyaringan $<$ sentence $>$. Penyaringan ini $<$ sentence $>$ dilakukan $<$ verb> oleh $_{\langle\text {partikel }>}$ rambut hidung ${ }_{<e n t i t y>}$ dan $_{<\text {conjunction }>\text { selaput }}$ lendir $<$ entity>. Contoh hasil output ditunjukkan pada tabel 8.

TABEL VIII

Hasil PengKodean LABEl Kata GanTI

\begin{tabular}{|l|l|l|}
\hline \multicolumn{1}{|c|}{ Kode } & \multicolumn{1}{c|}{ Parent } & \multicolumn{1}{c|}{ Kata / Kalimat } \\
\hline 1.1.1.1.1.1 & 1.1 .1 .1 & $\begin{array}{l}\text { Di dalam (x) Udara } \\
\text { mengalami }\end{array}$ \\
\hline $\begin{array}{l}1.1 .1 .1 . \\
1.1 .1\end{array}$ & 1.1 .1 .1 .1 & Penyaringan \\
\hline 1.1 .1 .1$. & 1.1 .1 .1$. & (x) dilakukan oleh \\
1.1 .1 .1 & 1.1 .1 & \\
\hline 1.1 .1 .1$. & 1.1 .1 .1$. & Rambut hidung \\
1.1 .1 .1 .1 & 1.1 .1 .1 & \\
\hline 1.1 .1 .1$. & 1.1 .1 .1$. & Selaput lendir \\
1.1 .1 .1 .2 & 1.1 .1 .1 & \\
\hline
\end{tabular}

7. Jika subyek berada di belakang, maka perlu penyesuaian. Pada umumnya kalimat yang digunakan adalah "tenggorokan bercabang menjadi bronkus". Tenggorokan adalah subyek di kalimat sebelumnya, jadi bisa langsung dikaitkan dengan kalimat sesudahnya. Namun terkadang subyek yang dirujuk berada di belakang ketika kalimatnya diubah menjadi "bronkus merupakan cabang dari tenggorokan". Jika diketemukan kalimat seperti itu maka akan diubah pengkodean dari kalimat paling belakang. Contoh hasil output ditunjukkan pada tabel 9.

TABEL IX

Hasil PengKodeAn PERPINDAHAN SUbyeK

\begin{tabular}{|c|c|l|}
\hline Kode & \multicolumn{1}{|c|}{ Parent } & \multicolumn{1}{|c|}{ Kata / Kalimat } \\
\hline 1.1 .1 .1 .3 .1 & 1.1 .1 .1 .3 & $\begin{array}{l}\text { Cabang (x) } \\
\text { merupakan }\end{array}$ \\
\hline 1.1 .1 .1 .3 .1 .1 & 1.1 .1 .1 .3 .1 & bronkus \\
\hline
\end{tabular}

\section{Pembangkitan Mind Map}

Proses pembangkitan mind map dijelaskan pada flowchart pada gambar 2. Proses diawali dengan memasukkan materi berdasarkan sub babnya, kemudian setiap paragraf dari materi tersebut dipisahkan menjadi per kalimat. Kemudian setiap kalimat akan masuk pada proses identifikasi kalimat.

Ada 3 proses pada tahap identifikasi kalimat yaitu pelabelan, pencarian kesamaan pembahasan kemudian pengkodean. Hasil dari proses identifikasi kalimat adalah kode dan kata. Kode dan kata tersebut kemudian digabungkan menjadi visualisasi sebuah mind map. Hasil dari pengkodean dan kata disimpan ke dalam database. Data itulah yang nantinya digunakan untuk mengenali keterkaitan inputan yang baru dimasukkan dengan mind map yang telah tercipta sebelumnya.

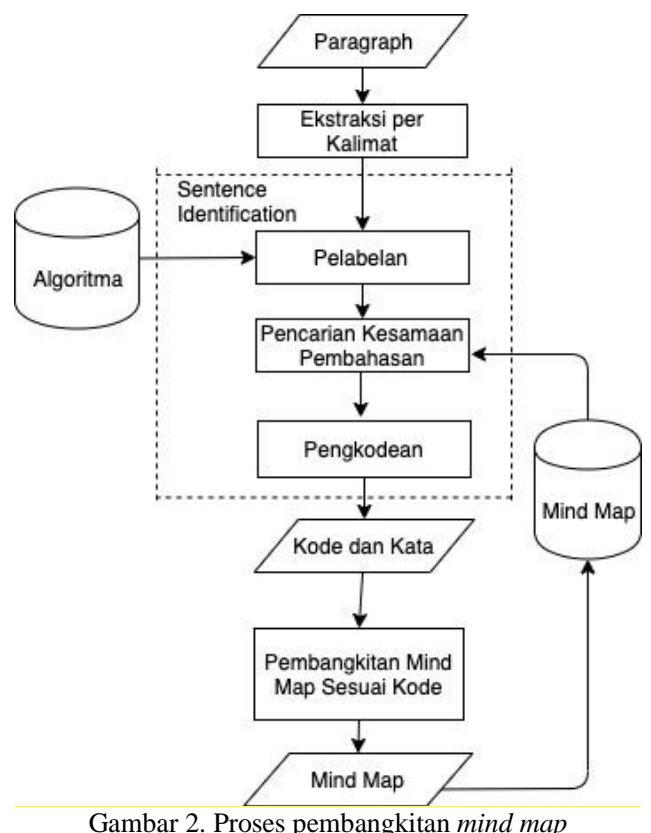

Misalkan kalimat pertama yang terdeteksi dari suatu paragraf yang diinputkan adalah "Alat pernapasan pada manusia terdiri dari rongga hidung, pangkal tenggorok, tenggorok (trakea), dan paru-paru". Kalimat tersebut akan masuk pada tahap identifikasi kalimat. Proses pertama dari tahap identifikasi kalimat adalah pelabelan kalimat. Ada 7 aturan yang digunakan untuk melakukan pelabelan kalimat. Hasil pelabelan kalimat tersebut adalah "Alat pernapasan

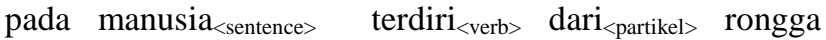




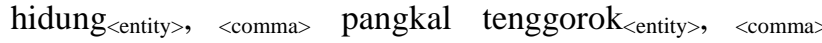
tenggorok (trakea) <entity>, <comma> dan paru-paru <entity>". Proses selanjutnya adalah pencarian kesamaan subjek pembahasan. Diketahui bahwa kalimat tersebut memiliki kesamaan pembahasan dengan poin pembahasan sebelumnya yaitu alat pernapasan manusia. Maka untuk tahap pengkodeannya akan merujuk pada sumber pernapasan manusia seperti tabel 4. Setelah diketemukan kemudian dilakukan penyesuaian kalimat, dengan mengganti symbol $\mathrm{x}$ terhadap kata yang sama. Penyesuain kalimat tersebut menjadi $\mathrm{x}$ terdiri dari rongga hidung, pangkal tenggorok, tenggorok (trakea), dan paru-paru

Kata yang telah memiliki kode kemudian akan disimpan ke dalam database mind map untuk nantinya digunakan sebagai dasar pencarian keterkaitan pembahasan. Selain disimpan pada database, kode dan kata kerja yang telah terbentuk akan divisualisasikan menjadi mind map. Hasil visualisasi ditunjukkan pada gambar 3.

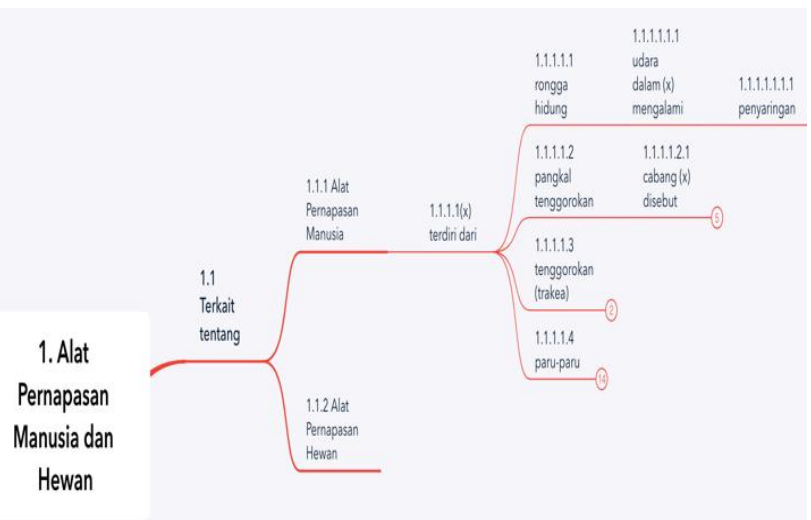

Gambar 3. Hasil pembangkitan mind map.

\section{Uji Coba}

Uji coba dilakukan menggunakan 8 materi pelajaran yang memiliki 1065 kalimat. Setiap informasi dari 1065 kalimat tersebut akan divisualisasikan menjadi mind map. Hasil pembangkitan mind map kemudian divalidasi oleh ahli. Proses validasi dilakukan dengan membandingkan hasil pembangkitan mind map dari metode yang diusulkan dengan hasil pembangkitan mind map yang telah dibuat sebelumnya oleh ahli [11]. Ahli akan membuat mind map terlebih dahulu, kemudian membandingkan jumlah cabang yang dihasilkan dan ketepatan kalimat yang digunakan pada setiap cabang. Selain itu eksperimen ini juga ingin menguji terkait adanya perbedaan gaya bahasa yang digunakan untuk buku dari kelas yang berbeda dan dari pengarang yang berbeda. Pengujian dilakukan dengan menggunakan metode yang sama untuk dua buku yang berbeda. Jika hasil akurasi mind map yang dihasilkan berbeda maka bisa disimpulkan bahwa penggunaan gaya bahasa dapat mempengaruhi hasil kinerja metode.

\section{HASIL DAN PEMBAHASAN}

Detil dari judul materi dan jumlah kalimat yang digunakan saat eksperimen ditunjukkan pada tabel 10 .
TABEL X

JUdUl MATERI YANG DigUNAKAN SEBAGAi DATA

\begin{tabular}{|r|l|r|}
\hline No & \multicolumn{1}{|c|}{ Materi } & $\begin{array}{c}\text { Jumlah } \\
\text { Kalimat }\end{array}$ \\
\hline 1 & Perkembangbiakan Makhluk Hidup & 325 \\
\hline 2 & Penghantar Panas & 27 \\
\hline 3 & Tumbuhan Hijau & 83 \\
\hline 4 & Pesawat Sederhana & 80 \\
\hline 5 & Perubahan Benda & 60 \\
\hline 6 & Daur Air & 65 \\
\hline 7 & Organ Tubuh Manusia dan Hewan & 323 \\
\hline 8 & Ciri Khusus Makhluk Hidup & 102 \\
\hline & Total Kalimat & 1065 \\
\hline
\end{tabular}

Hasil eksperimen kemudian masuk pada tahap validasi. Pada tahap awal validasi, ahli membuat mind map sesuai aturan pembuatan mind map yang telah ditentukan. Kemudian hasil mind map yang terbentuk dari ahli dibandingkan dengan mind map yang dibentuk dari metode yang diusulkan Aturan penilaian kesamaan mind map dijelaskan sebagai berikut:

1. Dianggap sama jika secara konsep memiliki kesamaan pembahasan walaupun hasil dari mind map berbeda. Misalkan dari kalimat "Udara masuk ke paru-paru karena dua hal. Pertama karena kontraksi otot antartulang rusuk, sehingga tulang rusuk terangkat. Kedua karena kontraksi diafragma, sehingga diafragma mendatar ". Hasil pembangkitan mind map ditunjukkan oleh gambar 4 dan gambar 5 . Walaupun berbeda namun memiliki konsep yang sama sehingga dianggap mirip.

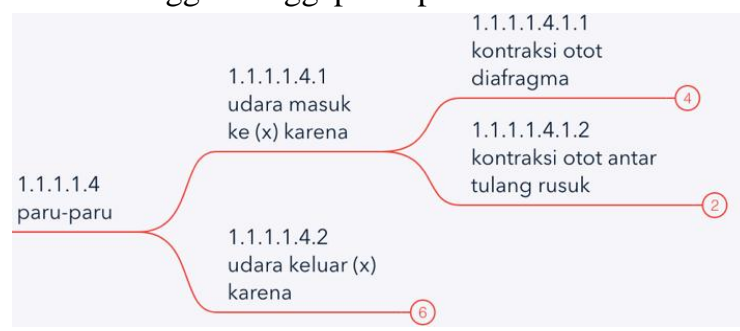

Gambar 4. Pembangkitan mind map versi 1

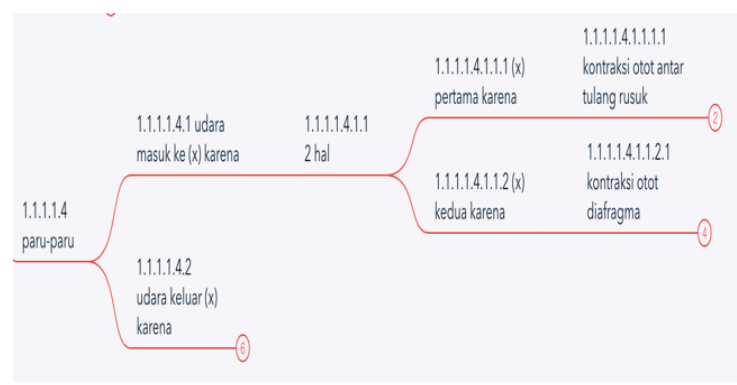

Gambar 5. Pembangkitan mind map versi 2

2. Dianggap berbeda jika ada perbedaan cabang yang diakibatkan tidak bisanya suatu kalimat dikonversi menjadi mind map. Misalkan ketika ada penambahan kalimat yang tidak bisa terdeteksi. Contoh kalimatnya "Masuk dan keluarnya udara pernapasan yang 
disebabkan oleh naik dan turunnya tulang rusuk disebut pernapasan dada". Pada mind map kedua ia tidak membentuk cabang, maka dianggap memiliki 2 perbedaan cabang dari yang aslinya. Contoh hasil mind map yang berbeda ditunjukkan oleh gambar 6 .

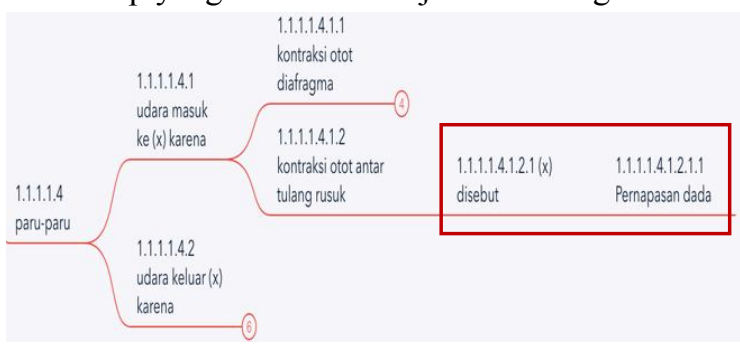

Gambar 6. Hasil Penambahan Cabang

Tabel 11 menunjukkan akurasi hasil pembangkitan mind map yang telah dilakukan. Akurasi didapatkan dengan membandingkan hasil mind map yang dibuat oleh ahli dan yang dibuat oleh metode yang diusulkan.

TABEL XI

JUMLAH NODE DAN RELASI SETIAP MATERI

\begin{tabular}{|c|r|r|r|r|}
\hline Materi & \multirow{2}{*}{$\begin{array}{c}\text { Jumlah } \\
\text { Kalimat }\end{array}$} & \multicolumn{2}{|c|}{ Jumlah Cabang } & \multirow{2}{*}{$\begin{array}{c}\text { Akurasi } \\
\text { Metode }\end{array}$} \\
\cline { 3 - 4 } & & $\begin{array}{c}\text { yang } \\
\text { Diusulkan }\end{array}$ & & \\
\hline 1 & 325 & 220 & 271 & $81 \%$ \\
\hline 2 & 27 & 17 & 22 & $77 \%$ \\
\hline 3 & 83 & 70 & 85 & $83 \%$ \\
\hline 4 & 80 & 78 & 90 & $86 \%$ \\
\hline 5 & 60 & 48 & 57 & $84 \%$ \\
\hline 6 & 65 & 73 & 29 & $79 \%$ \\
\hline 7 & 323 & 304 & 364 & $84 \%$ \\
\hline 8 & 102 & 60 & 72 & $83 \%$ \\
\hline Total & 1065 & 870 & 989 & $82 \%$ \\
\hline
\end{tabular}

Jumlah cabang yang dihasilkan tergantung dari kepadatan konten dari bacaan yang digunakan. Tata cara penulisan untuk materi di kelas 5 dan 6 tidak memiliki perbedaan yang signifikan. Hal tersebut terbukti dari dapat digunakannya rule yang sama untuk kelas yang berbeda. Pembangkitan mind map sangat bergantung pada kesamaan kata suatu kalimat dengan kalimat sebelumnya, sehingga walapun konteksnya sama, belum tentu kedua informasi tersebut dapat bergabung. Beberapa kalimat pada materi tidak hanya berbentuk kalimat deksriptif, namun juga berupa stimulus. Misalkan ketika sebuah materi membahas tentang kelelawar, di bagian awal ada stimulus berupa cerita terkait kelelawar. Setelah itu baru masuk ke konteks pembahasan terkait kelelawar. Hal inilah yang perlu difilter agar informasi yang berupa stimulus tidak masuk pada mind map.

\section{KESIMPULAN}

Hasil eksperimen yang telah dilakukan menunjukkan bahwa metode otomatisasi pembangkitan mind map berbasis analisis struktur kalimat ini bisa bekerja dengan baik. Metode yang diusulkan dapat digunakan untuk mebangkitkan mind map dan memvisualisasikan informasi buku teks akademik. Aturan yang dibuat pada metode ini dimungkinkan bisa berkembang sesuai dengan konteks informasi yang digunakan. Setiap jenis informasi memiliki pola yang berbeda oleh sebab itu sebaiknya pola dapat di perbaharui secara realtime sesuai data latih yang pernah digunakan. Hal tersebut akan membuat metode yang diusulkan dapat memiliki akurasi yang baik untuk berbagai macam teks informasi.

\section{UCAPAN TERIMA KASIH / ACKNOWLEDGMENT}

Terima kasih kepada Kementerian Riset dan Pendidikan Tinggi Indonesia yang telah mendukung penelitian ini.

\section{REFERENSI}

[1] R. Yulianto and S. Mariyah, "Building Automatic Mind Map Generator For Natural Disaster News in Bahasa Indonesia," in International Conference on Information Technology Systems and Innovation (ICITSI), Bandung, 2017.

[2] S. F. Kusuma, D. O. Siahaan, C. Fatichah and M. F. Naufal, "Automatic Question Generation With Classification Based On Mind Map," in JCSSE, Thailand, 2019.

[3] D. Dewantara, "The Effect of Learning with The Mindmapping Method Using Imindmap towards Student's Analytical Ability," Indonesian Journal of Science and Education, vol. 3, no. 1, pp. 1014, 2019.

[4] A. Suyanto, "The Effectiveness Of Mindmapping In Improving Students' Writing Skill Viewed From Their Iq," Indonesian Journal of English Education, vol. 2, no. 2, pp. 101-119, 2015.

[5] R. Wette, "Using mind maps to reveal and develop genre knowledge in a graduate writing course," Journal of Second Language Writing, vol. 38, pp. 58-71, 2017.

[6] Hapidin, Y. Pujianti and I. Juniasih, "The Effectiveness of Using Mind Mapping Method to Improve Child Development Assessment," Jurnal Pendidikan Usia Dini, vol. 13, no. 1, pp. 172186, 2019.

[7] A. Saelan and A. Purwarianti, "Generating Mind Map from Indonesian Text using Natural Language Processing Tools," in The 4th International Conference on Electrical Engineering and Informatics (ICEEI 2013), Malaysia, 2013.

[8] M. Elhoseiny and A. Elgammal, "English2MindMap: an Automated System for MindMap Generation from English Text," in IEEE International Symposium on Multimedia, Irvine CA, 2012.

[9] K. K. M, M. G., Y. G. Krishna, G. Shibu and G. V. Uma, "Automatic Concept Map Generation For Learning Engineering Mechanics," International Journal of Soft Computing and Artificial Intelligence, vol. 3, no. 2, pp. 23-25, 2015.

[10] I. S. Yliopisto, Automatic Contruction of Concept Map, Findland: Faculty of Science and Forestry, 2016.

[11] C. Z. Aguiar, D. Cury and A. Zouaq, "Automatic Construction Of Concept Maps From Texts," in Proc. of the Seventh Int. Conference on Concept Mapping, Estonia, 2016.

[12] K. Zubrinic, I. Obradovic and T. Sjekavica, "Implementation of method for generating concept map from unstructured text in the Croatian language," in 2015 23rd International Conference on Software, Telecommunications and Computer Networks (SoftCOM), Split, Croatia, 2015.

[13] A. Nugumanova, M. Mansurova, E. Alimzhanov, D. Zyryanov and K. Apayev, "Automatic generation of concept maps based on collection of teaching materials," in 4th International Conference on Data Management Technologies and Applications, 2015.

[14] S. Basuki and S. F. Kusuma, "Automatic Question Generation For $5 \mathrm{w}-1 \mathrm{~h}$ Open Domain Of Indonesian Questions By Using Syntactical Template-Based Features From Academic Textbooks," 
Journal of Theoretical and Applied Information Technology, vol. 96, no. 12, pp. 3908-3923, 2018.

[15] L. M. D. Araujo, "Automatic Tagging as a Support Strategy for Creating Knowledge Maps," Systematics, Cybernet and Informatics, vol. 15, no. 3, pp. 32-40, 2017.
[16] A. S. Yazid and A. Fatwanto, "Penentuan Kelas Kata Pada Part Of Speech Tagging Kata Ambigu Bahasa Indonesia," Jurnal Informatika Sunan Kalijaga, vol. 2, no. 3, pp. 157-166, 2018.

[17] N. Indrawati, M. A. Bijaksana and R. D. Agustin, "Pelabelan Peran Semantis Menggunakan Tata Bahasa Khusus," Jurnal Masyarakat Telematika dan Informasi, vol. 4, no. 2, pp. 85-108, 2013. 